\title{
Multiple sclerosis, fatigue and sleep disorders: beyond the clinical relapses
}

\author{
Esclerose múltipla, distúrbios do sono e fadiga: além dos surtos clínicos
}

Tarso Adoni

Hospital Sírio Libanês, Centro de Esclerose Múltipla, São Paulo SP, Brasil.

Correspondence:

Tarso Adoni; Rua Adma

Jafet, 74/cj. 121;01308-050

São Paulo SP, Brasil.

E-mail: tarso@dfvneuro.com.br

Conflict of interest:

There is no conflict of interest to declare.

Received 09 May 2016 Accepted 11 May 2016

\section{(c) BY}

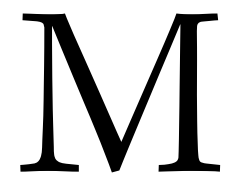

ultiple sclerosis (MS) is a chronic and debilitating immune-mediated disease affecting the central nervous system, whose clinical course, with its almost uncountable associated symptoms, presents as a challenge for the treating staff team ${ }^{1}$. Fatigue is the most disabling symptom of MS, affecting $75-90 \%$ of patients and can be defined as "a subjective lack of physical or mental energy that is perceived by the individual or caregiver to interfere with usual and desired activities",2.3. In a nutshell, fatigue has at least three dimensions: (1) physical, characterized by reduced motor performance at daily tasks; (2) cognitive, characterized by deterioration of time response, alertness and concentration; and (3) social, characterized by behavior of avoiding to meet people and to take part in outdoor events ${ }^{4}$. Fatigue in MS is not provoked by one single but by many causes concurrently. The main factors associated with fatigue in MS are MS itself (demyelination and axonal loss, also known as "primary fatigue"), complications related to MS (pain, cognitive impairment, spasticity, gait disorders, among others), medications, depression and sleep problems ${ }^{5}$. The presence of so many factors involved in the pathogenesis and/or exacerbation of fatigue in patients with MS makes it extremely hard to be quantified, which is almost always done incompletely.

Sleep disorders in MS and its relation with fatigue have been recently highlighted, despite the lack of published papers addressing this question ${ }^{6,7,89}$. Taking into account the scenario of scarcity of scientific studies linking sleep disorders and MS, in this issue of Arquivos de Neuropsiquiatria, Braga et al. ${ }^{10}$ studied the correlation among excessive daytime sleepiness (EDS), fatigue and functional disability measured by EDSS (Expanded Disability Status Scale). A retrospective review of 912 medical records was performed and 122 patients were included: 82 (67\%) patients had relapsing-remitting multiple sclerosis (RRMS), 15 (12\%) had primary progressive disease (PPMS) and $25(21 \%)$ had secondary progressive multiple sclerosis (SPMS). Beck's depression inventory was also analyzed, since depression is a common finding in MS patients and is usually associated to fatigue and sleep disorders ${ }^{2}$.

Braga et al. ${ }^{10}$ are faced with problems arising from the retrospective study design, such as the lack of polysomnographic (PSG) studies for a better characterization of sleep disorders, the absence of neuropsychological evaluation, and the small number of patients with progressive forms of MS, mainly secondary progressive MS. A recent published review addressing the specific issue of sleep disorders in MS draws attention to the occurrence of obstructive and central sleep apnea in this population, particularly in those patients with brainstem lesions ${ }^{11}$. Interestingly, patients with MS suffering from obstructive sleep apnea complain more about fatigue than overt EDS. On the other hand, Veauthier et al. ${ }^{12}$ did not find correlation between PSG findings and poor sleep quality in MS patients but did show a corrlation with depression, as measured by Beck Depression Inventory. Cognitive impairment can be detected in $40 \%$ to $70 \%$ of patients with MS and the interaction of fatigue and cognitive disturbances is well established, although the exact mechanism remains unclear ${ }^{13}$. Finally, patients with SPMS without evidence of inflammatory activity represent a huge therapeutic challenge and more detailed 
information about sleep quality in this specific population could help clinicians to better manage their patients ${ }^{14}$.

Braga et al. add a contribution in the study of MS and its comorbidities, as they report that patients with RRMS who experienced sleepiness and fatigue (63.1\%) suffered from moderate to severe depression ( $p=0.001)$, strengthening the relationship among fatigue, EDS and depression in patients with RRMS and also reinforcing the high frequency of fatigue and its association with EDS in patients with MS.

From a practical point of view, the take-home messages that can be extracted from the article are: (1) Inquire about the quality of sleep of your MS patients; (2) diagnose and treat depression when present. One should keep in mind that fatigue and sleep quality can improve significantly when depression is treated ${ }^{15}$.

\section{References}

1. Polman $\mathrm{CH}$, Reingold SC, Banwell B, Clanet M, Cohen JA, Filippi M et al. Diagnostic criteria for multiple sclerosis: 2010 revisions to the McDonald criteria.Ann Neurol. 2011;69(2):292-302. doi:10.1002/ana.22366

2. Khan F, Amatya B, Galea M. Management of fatigue in persons with multiple sclerosis. Front Neurol. 2014;5:177. doi:10.3389/fneur.2014.00177

3. Rammohan KW, Rosenberg JH, Lynn DJ, Blumenfeld AM, Pollak CP, Nagaraja HN. Efficacy and safety of modafinil (Provigil) for the treatment of fatigue in multiple sclerosis: a two centre phase 2 study. J Neurol Neurosurg Psychiatry. 2002;72(2):179-83. doi:10.1136/jnnp.72.2.179

4. Giovannoni G. Multiple sclerosis related fatigue.J Neurol Neurosurg Psychiatry. 2006;77(1):2-3. doi:10.1136/jnnp.2005.074948

5. Kos D, Kerckhofs E, Nagels G, D'hooghe MB, Ilsbroukx S. Origin of fatigue in multiple sclerosis: review of the literature. Neurorehabil Neural Repair. 2008;22(1):91. doi:10.1177/1545968306298934

6. Veauthier C, Paul F. Sleep disorders in multiple sclerosis and their relationship to fatigue. Sleep Med. 2014;5(1):5-4. doi:10.1016/j.sleep.2013.08.791

7. Braley TJ, Chervin RD. A practical approach to the diagnosis and management of sleep disorders in patients with multiple sclerosis. Ther Adv Neurol Disorder. 2015;8(6):294-310. doi:10.1177/1756285615605698

8. Dyken ME, Afifi AK, Lin-Dyken D.C Sleep-related problems in neurologic diseases. Chest. 2012;141(2):528-44. doi:10.1378/chest.11-0773
9. Trojan D, Kaminska M, Bar-Or A, Benedetti A, Lapierre Y, Costa D et al. Polysomnographic measures of disturbed sleep are associated with reduced quality of life in multiple sclerosis. J Neurol Sci. 2012;316(1-2):158-63. doi:10.1016/j.jns.2011.12.013

10. Braga DM, Prado GF, Bichueti DB, Oliveira EML. Positive correlation between functional disability, excessive daytime sleepiness, and fatigue in relapsing-remitting multiple sclerosis. Arq Neuropsiquiatr. 2014;74(6)433-8. doi:10.1590/0004-282X20160069

11. Braley TJ, Boudreau EA. Sleep disorders in multiple sclerosis. Curr Neurol Neurosci Rep. 2016;16(5):50. doi:10.1007/s11910-016-0649-2

12. Veauthier C, Gaede G, Radbruch H, Wernecke KD, Paul F. Poor sleep in multiple sclerosis correlates with beck depression inventory values, but not with polysomnographic data. Sleep Disord. 2016;2016(4):1-5. doi:10.1155/2016/8378423

13. Rocca MA, Amato MP, De Stefano N, Enzinger C, Geurts JJ, Penner IK et al. for the MAGNIMS Study Group. Clinical and imaging assessment of cognitive dysfunction in multiple sclerosis. Lancet Neurol. 2015;14(3):302-17. doi:10.1016/S1474-4422(14)70250-9

14. Sleeman KE, Higginson IJ. A psychometric validation of two brief measures to assess palliative need in patients severely affected by multiple sclerosis. J Pain Symptom Manage. 2013;46(3):406-12. doi:10.1016/j.jpainsymman.2012.08.007

15. Fragoso YD, Adoni T, Anacleto A, Gama PD, Goncalves MV, Matta APet al. Recommendations on diagnosis and treatment of depression in patients with multiple sclerosis. Pract Neurol. 2014;14(4):206-9. doi:10.1136/practneurol-2013-000735 